\title{
Inhibition of Protein Tyrosine Phosphatase 1B Improves IGF-I Receptor Signaling and Protects Against Inflammation-Induced Gliosis in the Retina
}

\author{
Ana I. Arroba ${ }^{1,2}$ and Ángela M. Valverde ${ }^{1,2}$ \\ ${ }^{1}$ Centro de Investigación Biomédica en Red de Diabetes y Enfermedades Metabólicas Asociadas (CIBERDEM), ISCIII, Madrid, Spain \\ ${ }^{2}$ Instituto de Investigaciones Biomédicas "Alberto Sols" (CSIC/UAM), Madrid, Spain
}

Correspondence: Ángela M. Valverde, Instituto de Investigaciones Biomédicas "Alberto Sols" (CSIC/ UAM), Madrid, Spain;

avalverde@iib.uam.es.

Ana I. Arroba, Centro de Investigación Biomédica en Red de Diabetes y Enfermedades Metabólicas Asociadas (CIBERDEM), ISCIII, Madrid, Spain;

aarroba@iib.uam.es.

Submitted: May 8, 2015

Accepted: November 8, 2015

Citation: Arroba AI, Valverde AM. Inhibition of protein tyrosine phosphatase 1B improves IGF-I receptor signaling and protects against inflammation-induced gliosis in the retina. Invest Ophthalmol Vis Sci. 2015;56:8031-8044. DOI:10.1167/ iovs.15-17234
Purpose. Insulin-like growth factor-I receptor (IGF-IR) signaling mediates retinal growth and survival and its failure may contribute to aggravate diabetic retinopathy (DR). Protein tyrosine phosphatase 1B (PTP1B) negatively modulates IGF-IR signaling, but its involvement in inflammation during DR remains unknown. We investigated whether PTP1B participates in the cross-talk between proinflammatory signaling pathways and IGF-IR-mediated signaling in the retina.

Methods. 661W photoreceptors or mouse retinal explants were treated with TNF $\alpha$, IL6, and IL1 $\beta$. Insulin-like growth factor-I receptor signaling cascade was evaluated in the absence or presence of PTP1B. $d b / d b$ mice were used to test a PTP1B inhibitor in retinal gliosis.

Results. 661W retinal cells and retinal explants responded to IGF-I by inducing IGF-IR tyrosine (13-fold) and Akt phosphorylations (7- and 3-fold for serine 473 and threonine 308, respectively). Cytokines triggered early activation of stress kinases (c-jun [NH2] terminal kinase [JNK] and p38 MAPK), resulting in insulin receptor substrate 1 (IRS1) serine 307 phosphorylation that precedes its degradation. Pretreatment of $661 \mathrm{~W}$ cells or retinal explants with cytokines upregulated PTP1B protein levels (1.45- and 4.5-fold, respectively), induced IRS1 degradation and decreased IGF-I-mediated IGF-IR/Akt phosphorylation. Silencing or deficiency in PTP1B ameliorated the negative effects of cytokines on IGF-IR signaling. Cytokines increased glial fibrillary acidic protein (GFAP) expression in retinal explants by 4.5fold, this response being reduced by 2 -fold with a PTP1B inhibitor. Protein tyrosine phosphatase 1B protein levels increased by 3 -fold in retinas from $d b / d b$ mice and its inhibition reduced gliosis.

Conclusions. Targeting PTP1B might be useful for modulating IGF-I effects in retinal cells during DR.

Keywords: PTP1B, IGF-I, IRS1, diabetic retinopathy, inflammation
$\mathrm{D}$ iabetic retinopathy (DR) is a major cause of blindness globally and a leading cause of legal blindness in the working age population of the developing world. ${ }^{1,2}$ Diabetes affects the entire neurovascular unit of the retina, with gradual neurodegeneration, gliosis, neuroinflammation, compromise of the vascular blood-retinal barrier, edema, angiogenesis, and eventual fibrosis. Although neurodegeneration and inflammation have been implicated in the etiology of $\mathrm{DR},{ }^{3-5}$ diagnosis and treatment of this disease are mainly focused on the vascular abnormalities that ultimately occur.

Type 2 diabetes mellitus (T2DM) is recognized as a low grade chronic inflammatory disease in which initially the infiltration of immune cells in adipose tissue generates a systemic proinflammatory milieu that negatively interferes with insulin signaling. ${ }^{6}$ Moreover, prolonged metabolic stress leads to a chronic state of overactivation of immune cells of the central nervous system (CNS), leading to neuroinflammation. ${ }^{7}$ Therefore, adipose-derived inflammatory mediators could be an important addition to local cytokines produced by CNS-resident microglia in boosting brain inflammation. A number of metabolic or molecular abnormalities associated to inflamma- tion have been detected in retinas of diabetic animals, patients, or in retinal cells exposed to elevated concentrations of glucose $^{8}$ raising the hypothesis that these defects might reflect an imbalance between pro- and anti-inflammatory cytokine expression. ${ }^{9-11}$

Insulin and insulin-like growth factor-I receptors (IR and IGF-IR, respectively) belong to the tyrosine kinase receptor superfamily. Activation of both receptors stimulates tyrosine phosphorylation of insulin receptor substrates (IRS) that act as docking proteins engaging the receptors with intracellular signaling pathways. Among these, activation of phosphatidylinositol (PI) 3-kinase/Akt is essential for the cell survival. ${ }^{12,13}$ The IGF-I/IGF-IR system is expressed in retinal neurons ${ }^{14,15}$ and IGF-I is a proliferation and differentiation factor for the neural retina. ${ }^{16}$

Recent evidences support the involvement of two recognized factors linking T2DM with neurodegeneration; the elevation of proinflammatory cytokines and the onset of insulin/IGF-I resistance. ${ }^{17}$ In T2DM, proinflammatory cytokines such as TNF $\alpha$ trigger phosphorylation of insulin receptor substrate 1 (IRS1) at serine 307 by stress kinases, ${ }^{18}$ which 
disrupts its interaction with the IR and blocks the intracellular actions of insulin in peripheral tissues. Likewise, excess of peripheral proinflammatory mediators, some of which can cross the blood-brain barrier, may trigger insulin/IGF-I resistance in the CNS, thereby weakening the neuroprotective signaling mediated by these molecules and this effect can contribute to the onset of neurodegenerative diseases. ${ }^{17}$ In this regard, it been demonstrated that IGF-I elicits neuroprotective effects in neurons exposed to several stressors including hypoxia-ischemia. ${ }^{19}$

Protein tyrosine phosphatase 1B (PTP1B), an ubiquitously expressed phosphatase, has emerged as a relevant modulator of IR and IGF-IR signaling pathways by its ability to dephosphorylate tyrosines within the catalytic domain in both receptors. ${ }^{20-22}$ In mice, deletion of the ptpn 1 gene increased insulin sensitivity in liver and skeletal muscle and protects against obesity. ${ }^{23,24}$ In the retina, PTP1B is expressed in rod photoreceptor cells ${ }^{25}$ and also targets IGF-IR-mediated signaling. ${ }^{26}$ However, the modulation of the signaling pathways activated by the IGF-IR and the impact of PTP1B inhibition in the presence of a proinflammatory environment in the retina remains unknown and is the aim of the present study.

\section{Materials ANd Methods}

\section{Reagents}

Fetal bovine serum (FBS) and culture media were from Invitrogen (Grand Island, NY, USA). Bovine serum albumin (BSA) was purchased from Sigma-Aldrich Corp. (St. Louis, MO, USA). IGF-I (human recombinant), IL1 $\beta$, IL6, and TNF $\alpha$ were purchased from Preprotech (London, UK). Noncompetitive PTP1B inhibitor was 3-(3,5-dibromo-4-hydroxy-benzoyl)-2-ethyl-benzofuran-6-sulfonicacid-(4-(thiazol-2-ylsulfamyl)-phenyl)amide (Catalog number 539741; Calbiochem, Darmstadt, Germany). Bradford reagent, acrylamide, immunoblot polyvinylidene difluoride (PVDF) membranes and chemiluminescent horseradish peroxidase (HRP) substrate were purchased from Bio-Rad (Madrid, Spain).

\section{Antibodies}

Anti-IGF-IR (sc-713), anti-phospho-Akt1/2/3 (Ser473; sc-7985R), anti-phospho-Akt1/2/3 (Thr308; sc-166646-R), anti-Akt1/2/ 3 (sc-8312), anti-JNK (sc-571), and anti-phospho p38 MAPK (Thr 180/Tyr182; sc-17852-R) antibodies were from Santa Cruz Biotechnology (Palo Alto, CA, USA). Anti-phospho IRS1 (Ser 307; 07-247), anti-p85 $\alpha$ (06-195) and anti-PTP1B (05-1087, recognizes cleavaged PTP1B) and anti-PTP1B (07-088) antibodies were purchased from Merk-Millipore (Merck KGaA, Darmstadt, Germany). Anti-phospho-IGF-IR $\beta$ (Tyr1135/1136; \#3024), anti-phospho Akt (Ser473; \#9272), anti-phospho JNK (Thr183/Tyr185) (\#4668), and anti-phospho p38 MAPK (\#9212) antibodies were purchased from Cell Signaling Technology (Danvers, MA, USA). Anti- $\alpha$-tubulin (T-0198) antibody was from Sigma-Aldrich Corp. and anti-glial fibrillary acidic protein (GFAP) antibody (z0334) was obtained from DAKO (Glostrup, Denmark).

\section{Cell Culture}

The $661 \mathrm{~W}$ cell line derived from immortalized cone photoreceptors, ${ }^{27}$ provided by Muayyad Al-Ubaidi (University of Oklahoma, Norman, OK, USA), was maintained in Dulbecco's modified Eagle's medium (DMEM) supplemented with 10\% (vol/vol) heat-inactivated FBS. For experiments, 661W cells were seeded at $75 \times 10^{3}$ cells/well in six-well plates. Confluent cells were grown in serum-free medium in the absence or presence of cytokines (CK; TNF $\alpha$, IL6, and IL1 $\beta ; 20 \mathrm{ng} / \mathrm{mL}$ each) for several time periods. In some experiments, after 24 hours of incubation with cytokines, IGF-I (10 nM) was added for the last 15 minutes.

\section{Retinal Explants}

Ex vivo assays were performed with retinas from 10 -week-old male $\mathrm{C} 57 \mathrm{BL} / 6$ mice, $d b /+$ and $d b / d b$ mice, purchased from Charles River Laboratories (Charles River, Barcelona, Spain), or with age-matched PTP1B-deficient $\left(\mathrm{PTP}^{-1-}\right)$ mice. $^{26}$ Mice were maintained in light/dark (12-hours light/12-hours dark), temperature $\left(22^{\circ} \mathrm{C}\right)$, and humidity-controlled rooms, and fed ad libitum with free access to water. All animal experimentation followed recommendations of the Federation of European Laboratory Animal Science Associations (FELASA) on health monitoring in accordance with the regulations of the Association for Research in Vision and Ophthalmology (ARVO). Animals were killed by cervical dislocation and eyes were enucleated. The lens, anterior segment, vitreous body, retinal pigment epithelium, and sclera were removed and the retina was cultured in R16 medium (provided by PA Ekstrom, Lund University, Sweden) with no additional serum. Retinas were stimulated with cytokines (CK; TNF $\alpha$, IL6, and IL1 $\beta ; 20 \mathrm{ng} / \mathrm{mL}$ each) and/or IGF-I ( $20 \mathrm{nM})$ at the time periods indicated in the figure legends.

\section{Quantitative Real-Time PCR Analysis}

Total RNA was extracted with Trizol (Fisher Scientific-USA, Waltham, MA, USA) and reverse transcribed using HighCapacity cDNA Reverse Transcription Kit (ThermoFisher Scientific, Madrid, Spain). Quantitative real-time PCR (qPCR) was performed with an ABI 7900 sequence detector (ThermoFisher Scientific). The primer-probe sets for mouse ptpn1 and $18 s$ were purchased as predesigned TaqMan gene expression (Life Technologies; catalog numbers Mm_00448427_m1 and

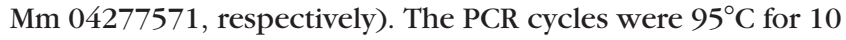
minutes, 40 cycles at $95^{\circ} \mathrm{C}$ for 15 seconds and $60^{\circ} \mathrm{C}$ for 60 seconds following the manufacturer's instructions (Applied Biosystems, Madrid, Spain).

\section{Transient Transfection With siRNA}

siRNA oligonucleotides were synthesized by Dharmacon RNAi Technologies (Fisher Scientific-USA). Targeted sequences for ptpn 1 were: 5'GGAGAAAGGCUCGUUAAAA3'; 5'GACCACA GUCGGAUUAAAU3'; 5'GGUUUGAAGUUGACACUAA3'; 5'UCG CGAAGCUUCCUAAGAA3' (sigENOME SMART pool, mouse ptpn1). 661 W cells and retinal explants were transfected with scrambled (siGENOME RISC-free Control siRNA; catalog number D-001220-01; Fisher Scientific-USA) or PTP1B siRNAs at $25 \mathrm{nM}$ concentration following manufacturer's instructions. After 36 hours, transfected cells and retinal explants were treated with cytokines (CK; $20 \mathrm{ng} / \mathrm{mL}$ ) for 24 hours, serumstarved for 2 hours and further stimulated with IGF-I $(10 \mathrm{nM})$ for 15 minutes. Scrambled or PTP1B siRNA oligos were present during treatment with cytokines and IGF-I.

\section{Western Blotting}

Proteins were resolved using denaturing SDS-PAGE, and transferred to PVDF membranes (Bio-Rad). ${ }^{26}$ Membranes were blocked using 5\% nonfat dried milk or 3\% BSA in $10 \mathrm{mM}$ Tris$\mathrm{HCl}, 150 \mathrm{mM} \mathrm{NaCl}, \mathrm{pH} 7.5$ (TBS), and incubated overnight with antibodies in $0.05 \%$ Tween-20-TBS. Immunoreactive bands were visualized using the enhanced chemioluminiscence reagent (Bio-Rad). Levels of phosphorylated proteins 
A
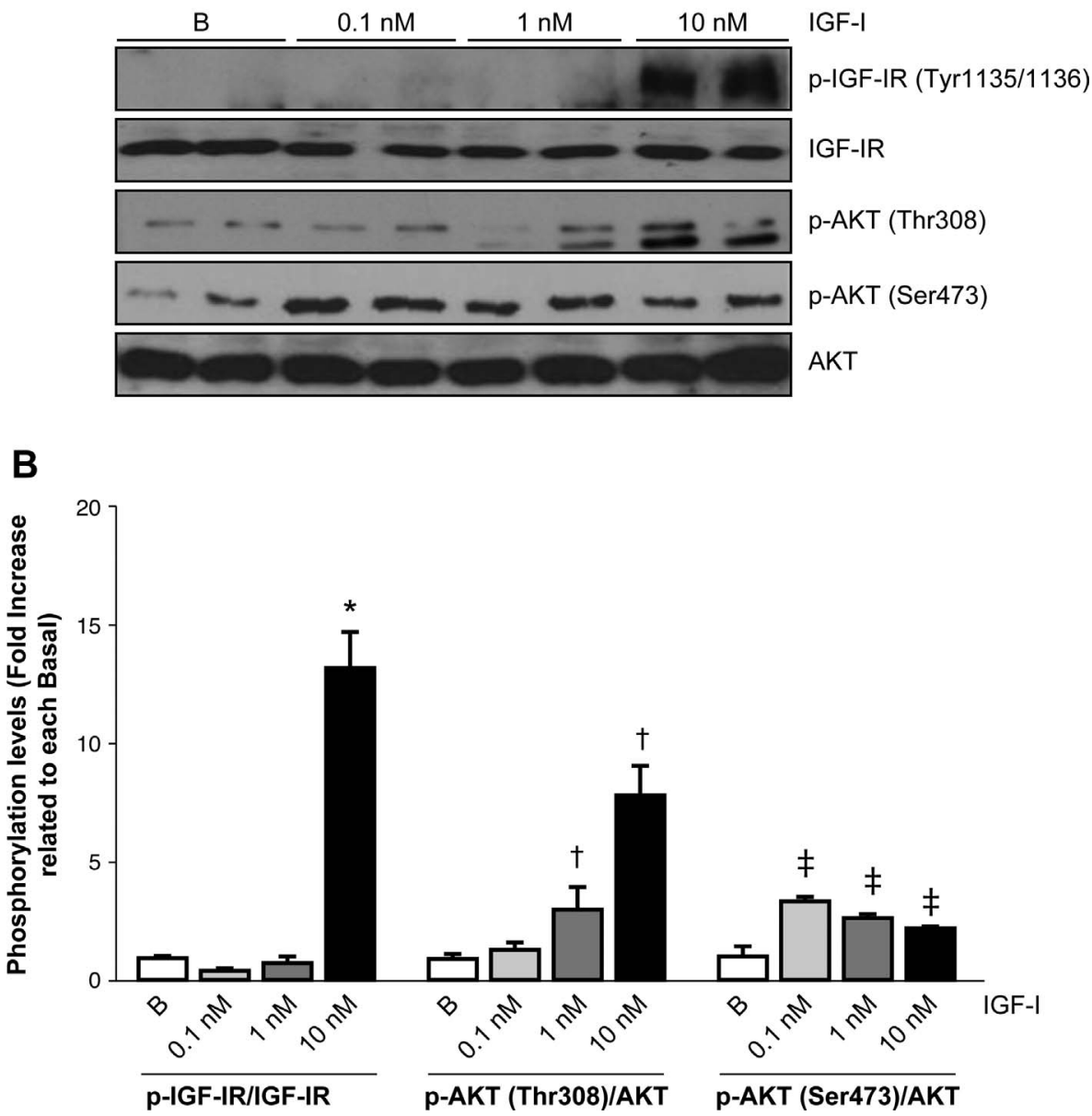

FIGURE 1. Insulin-like growth factor-IR-mediated Akt signaling in $661 \mathrm{~W}$ retinal cells. Confluent $661 \mathrm{~W}$ cells were serum-starved for 2 hours and then stimulated with various doses of IGF-I for 15 minutes. Protein extracts (30 $\mu \mathrm{g})$ were separated by SDS-PAGE and analyzed by Western blot with the anti-phospho IGF-IR (Tyr1135/1136), anti-IGF-IR, anti-phospho Akt (Ser473), anti-phospho Akt (Thr308), and anti-Akt antibodies. (A) Representative autoradiograms are shown ( $n=3$ independent experiments). (B) The blots were quantitated by scanning densitometry. Levels of phosphorylated IGF-IR and Akt were normalized by their corresponding levels of total IGF-I or Akt protein, respectively, that were used as loading control. Results are expressed as fold increase of IGF-I stimulation and are means \pm SEM. Data were analyzed by 1-way ANOVA followed by Bonferroni $t$-test. Comparisons were ${ }^{*} \dagger \neq P \leq 0.05$ IGF-I stimulation versus their corresponding nonstimulated basal (B).

(pIGF-IR and pAkt) were normalized by levels of corresponding total (IGF-IR and Akt) proteins that were used as loading controls. These results are expressed as fold change of IGF-I stimulation related to each basal. Levels of PTP1B were normalized by $\alpha$-tubulin.

\section{PTP1B Enzymatic Activity}

PTP1B phosphatase activity was determined by measuring phosphate release using a synthetic monophosphotyrosylcontaining peptide and the malachite green assay (Ref. 17125; Millipore) as described. ${ }^{28}$

\section{Histologic Analysis and Immunofluorescence}

Retinal explants were fixed in $4 \%$ paraformaldehyde for 8 hours, washed in TBS containing $0.1 \%$ (wt/vol) BSA and $0.1 \%$ (vol/vol) Triton X-100 (this buffer was used for all subsequent washes) and blocked and permeated for 2 hours in TBS containing 3\% (wt/vol) BSA and 1\% (vol/vol) Triton X-100. The samples were incubated overnight in a humid chamber at $4^{\circ} \mathrm{C}$ with rabbit anti-GFAP antibody in blocking solution. Retinal explants were washed and incubated for 90 minutes with antirabbit immunoglobulin antibody conjugated to Alexa 488 (Molecular Probes, Eugene, OR, USA), washed, and mounted with mounting medium (Fluoromount G). Staining was observed with a laser confocal microscope LSM710 (Carl Zeiss Microscopy GmbH, Göttingen, Germany). For quantification of GFAP immunostaining, mean fluorescence density was measured in five fields per retina using the ImageJ software (http:// imagej.nih.gov/ij/; provided in the public domain by the National Institutes of Health, Bethesda, MD, USA).

\section{Statistical Analysis}

Densitometry of the Western blots was performed using the ImageJ program. Values in all graphs represented the mean \pm SEM. Statistical tests were performed using SPSS 21.0 for Windows (SPSS, Inc., IBM, Armonk, NY, USA). Data were analyzed by 1- or 2-way ANOVA followed by Bonferroni $t$-test or by paired $t$-test when comparisons were among two groups. Differences were considered significant at $P \leq 0.05$. 
A

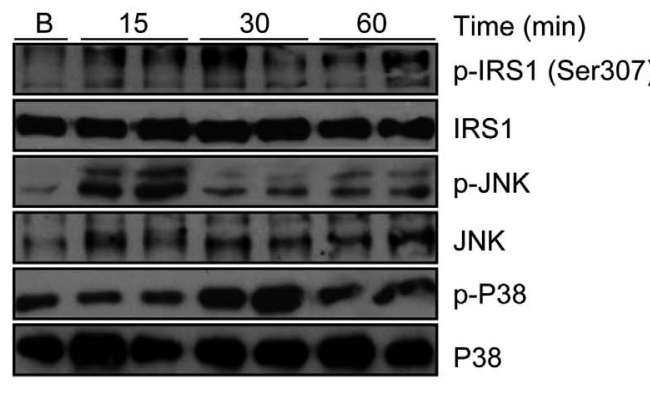

C

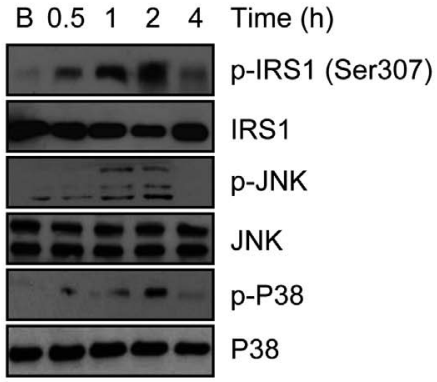

B

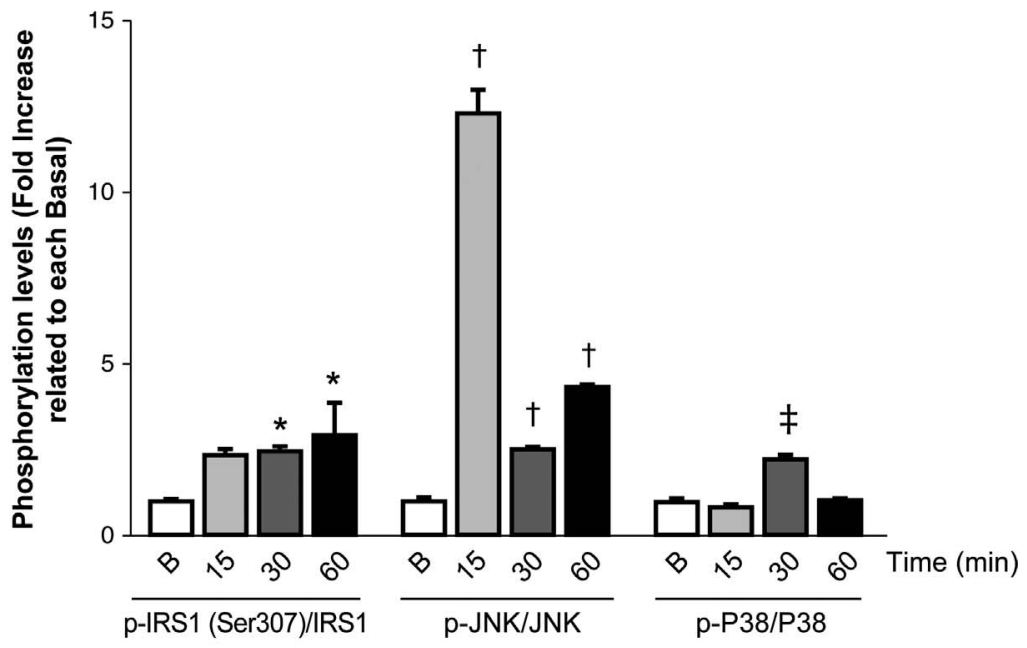

D

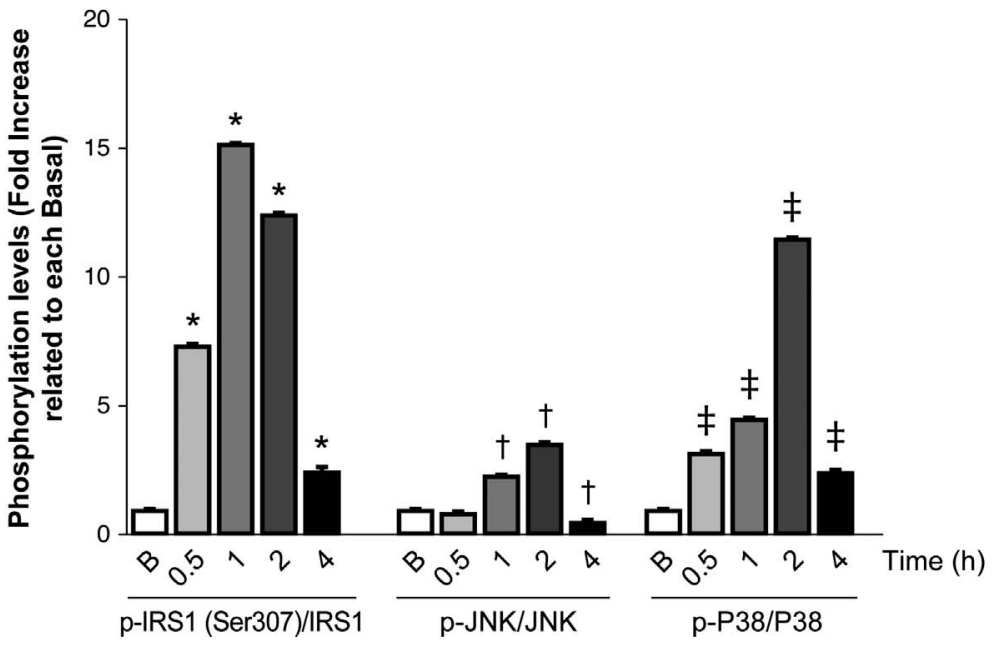

FIGURE 2. A combination of proinflammatory cytokines (CK) induced the activation of stress kinases and the phosphorylation of IRS1 at serine 307 in retinal cells. (A) $661 \mathrm{~W}$ photoreceptors and (C) mouse retinal explants were stimulated with a combination of proinflammatory cytokines containing TNF $\alpha$, IL6, and IL1 $\beta$ (CK; $20 \mathrm{ng} / \mathrm{mL}$ each) at the indicated time-periods. Protein extracts (50 $\mu \mathrm{g}) \mathrm{were}$ separated by SDS-PAGE and the phosphorylation of IRS1 (Ser307), JNK (Thr183/Tyr185), and p38 MAPK (Thr180/Tyr182) was analyzed by Western blot with the corresponding antibodies. Total levels of IRS1, JNK, and p38 MAPK were also analyzed. Representative autoradiograms are shown $(n=3$ independent experiments). In (B) and (D) the results are means \pm SEM. Data were analyzed by 1-way ANOVA followed by Bonferroni $t$-test. Comparisons were ${ }^{*} \dagger \neq P \leq 0.05$ cytokines (CK) versus their corresponding nonstimulated basal (B).

\section{Results}

\section{IGF-I Induces Phosphorylation of the IGF-IR and Akt in Retinal Cells}

Insulin-like growth factor-I and its receptor (IGF-IR) are expressed in the inner retina, ${ }^{14,15}$ and retinal microvascular cells produce, ${ }^{29}$ and respond to IGF-I in vitro. ${ }^{30}$ Because activation of the IGF-IR/Akt signaling cascade protects mammalian cell types against death signals, ${ }^{31}$ we characterized the activation of this pathway in $661 \mathrm{~W}$ cells that expressed cone photoreceptor markers. ${ }^{27}$ As shown in Figures 1A and 1B, in $661 \mathrm{~W}$ photoreceptors phosphorylation of the IGF-IR at tyrosines 1135/1136 within the catalytic domain and Akt at threonine 308 occurred in a dose-dependent manner; being maximal effect elicited at $10 \mathrm{nM}$ (13-fold for IGF-IR tyrosine phosphorylation and 7-fold for Akt threonine 308 phosphorylation). Maximal phosphorylation of Akt at serine 473 (3-fold), which was mediated by the mTORC 2 complex, ${ }^{32}$ was detected at $0.1 \mathrm{nM}$. These results indicate that $661 \mathrm{~W}$ retinal cells respond to IGF-I and agree with the activation of IGF-IR/Akt signaling by IGF-I in retinal explants. ${ }^{26}$

\section{Retinal Cells Respond to Proinflammatory Cytokines by the Activation of Stress Kinases}

Because proinflammatory cytokines were components of the diabetic milieu in the retina, ${ }^{33}$ we inspected the sensitivity of retinal cells to the activation of stress kinases in response to proinflammatory cytokines. A mixture of proinflammatory cytokines (TNF $\alpha$, IL6, and IL1 $\beta$ ) was used to stimulate $661 \mathrm{~W}$ 
A

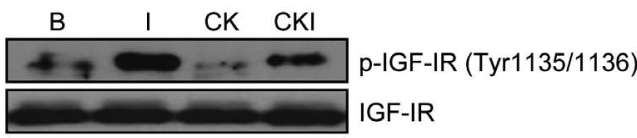

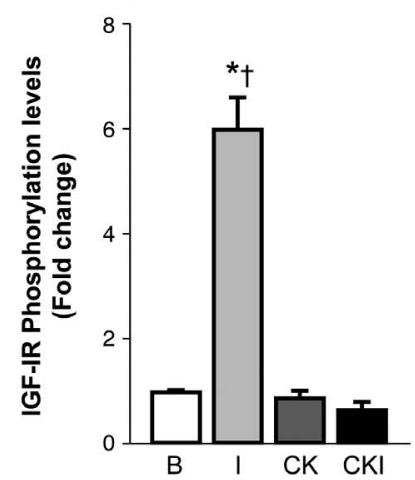

B
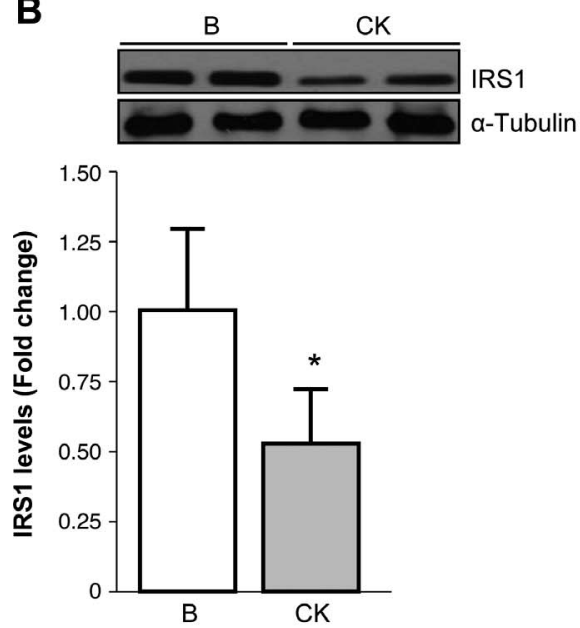

C
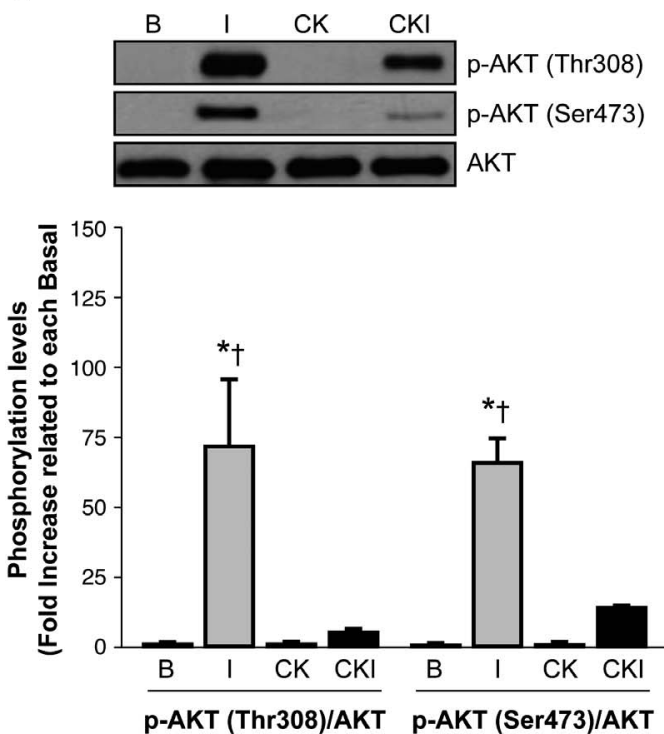

D
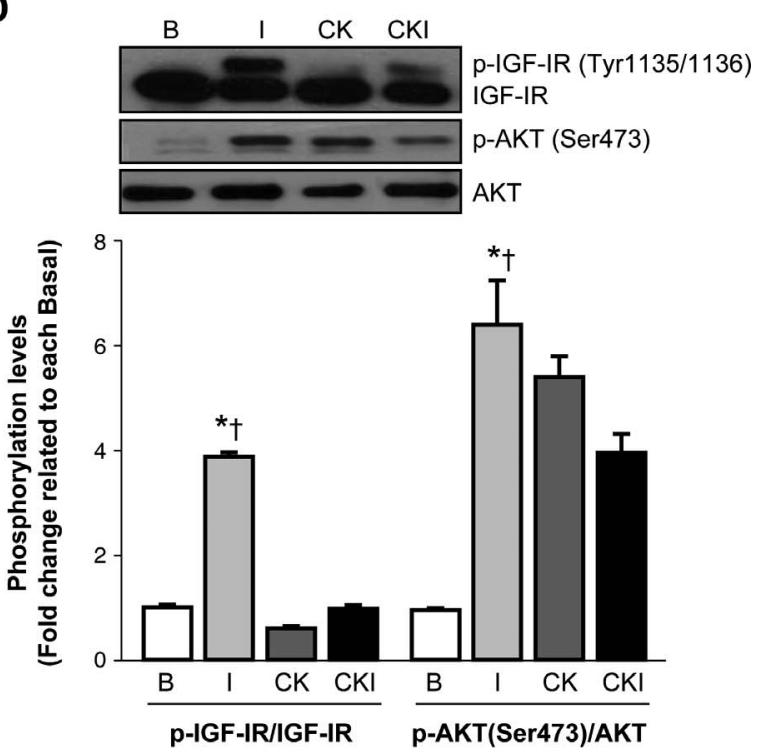

E
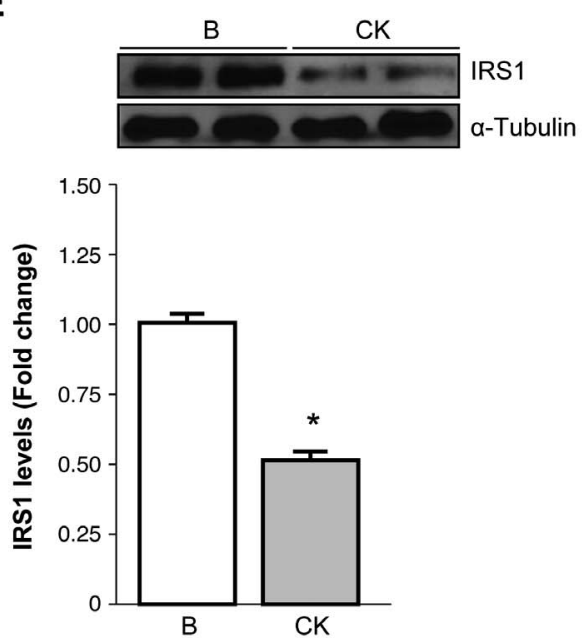
pAkt) were normalized by levels of their corresponding total IGF-IR and Akt protein that were used as loading controls. These results are expressed as fold change of IGF-I stimulation related to each basal. Alpha-tubulin was used as a loading control for IRS1. The results are means \pm SEM. Data were analyzed by 1- or 2-way ANOVA followed by Bonferroni $t$-test. In $(\mathbf{A}, \mathbf{C}, \mathbf{D})$ comparisons were ${ }^{*} \boldsymbol{P} \leq 0.05$ IGF-I (I) versus nonstimulated basal (B); $\dagger P \leq 0.05$ cytokines plus IGF-I (CKI) versus IGF-I (I). In (B) and (E) results are means \pm SEM. Data were analyzed by paired $t$-test. Comparisons were ${ }^{*} P \leq 0.05$ cytokines $(\mathrm{CK})$ versus nonstimulated basal $(\mathrm{B})$.

cells and phosphorylations of c-jun (NH2) terminal kinase (JNK) and p38 mitogen-activated protein kinase (MAPK) were analyzed. As shown in Figures 2A and 2B, phosphorylation of JNK and p38 MAPK was very rapid and peaked at 15 and 30 minutes, respectively, after addition of cytokines. A 14- and 2.5fold increase in JNK and p38 MAPK phosphorylations, respectively, were found at these time periods.

We also analyzed these responses in the whole retina using retinal explants that preserved the sensitivity to extracellular stimuli $^{26}$ and found maximal JNK (4-fold) and p38 MAPK (12fold) phosphorylations at 1 and 2 hours, respectively (Figs. 2C, 2D).

Serine phosphorylation of IRS1, an immediate downstream target of the IGF-IR, precedes its ubiquitination and proteasomal degradation. ${ }^{34,35}$ Among potential IRS1 serine kinases, JNK has been extensively studied in insulin resistant states. ${ }^{36}$ Treatment with cytokines increased IRS1 serine 307 phosphorylation in $661 \mathrm{~W}$ cells by 3.5 -fold and, importantly, similar effect occurred in retinal explants where cytokines increased this response by 15 -fold (Figs. 2A-D).

\section{Proinflammatory Cytokines Negatively Interfered With IGF-IR/Akt Signaling in Retinal Cells}

Because proinflammatory cytokines trigger early and long-term signaling pathways that negatively modulate IGF-IR-mediated signaling, ${ }^{37}$ we analyzed this cross-talk in retinal cells. $661 \mathrm{~W}$ cells were pretreated with cytokines for 24 hours, serumstarved for 2 hours, and further stimulated with IGF-I (10 nM) for 15 minutes. This prolonged treatment with cytokines did not induce death of $661 \mathrm{~W}$ cells (results not shown). Insulinlike growth factor-I-induced IGF-IR tyrosine phosphorylation decreased by 6.5 -fold in $661 \mathrm{~W}$ cells pretreated with cytokines as compared with nonpretreated cells (CKI versus I; Fig. 3A). Downstream the IGF-IR, IRS1 levels significantly decreased (0.5-fold) in the presence of cytokines, reflecting its proteosomal degradation (Fig. 3B). Likewise, the response to IGF-I in the phosphorylation of Akt (threonine 308 and serine 473) was decreased by 7.5- and 3.5-fold, respectively, in cells pretreated with cytokines compared with nonpretreated cells (CKI versus I; Fig. 3C).

To demonstrate the physiological relevance of these data, mouse retinas were incubated ex vivo with cytokines for 24 hours and then stimulated with IGF-I $(20 \mathrm{nM})$ for 30 minutes. Cell death was not detected in retinal explants treated with cytokines (results not shown). Pretreatment with cytokines reduced the response to IGF-I in inducing IGF-IR tyrosine phosphorylation at basal levels (CKI versus I) and also reduced by 1.75 fold Akt phosphorylation at serine 473 as compared with explants that did not receive proinflammatory stimuli (CKI versus I; Fig. 3D). Notably, in retinal explants the treatment with cytokines increased basal Akt phosphorylation by 5.5 fold (CK versus $\mathrm{B}$ ), but this response was not further increased by IGF-I stimulation, reflecting the lack of sensitivity to IGF-I. Degradation of IRS1 was found in retinal explants cultured in the presence of cytokines compared with the basal condition (0.5-fold decrease in CK versus $B$; Fig. 3E).

\section{Modulation of PTP1B Expression and Enzymatic Activity in Retinal Photoreceptors and Retinal Explants Under Proinflammatory Conditions}

We have demonstrated that PTP1B is elevated in the retina of diabetic mice and the modulation of IGF-IR tyrosine phosphorylation by this phosphatase in retinal explants. ${ }^{26}$ Based on that, we analyzed the effect of the proinflammatory milieu on PTP1B expression in photoreceptors. As Figure 4A showed, PTP1B mRNA was elevated by 2.5 -fold in $661 \mathrm{~W}$ cells treated with cytokines. Moreover, cytokines induced the cleavage of the protein with a similar pattern reported in platelets ${ }^{38}$ and also increased PTP1B protein levels by 1.5 -fold (Fig. 4B) and enzymatic activity by 2 -fold reflecting the activation of the phosphatase activity associated to this cleavage ${ }^{38}$ (Fig. 4C). In agreement with data in peripheral tissues, ${ }^{39}$ PTP1B mRNA and protein expression were also increased by 3.8- and 4.5-fold, respectively, in retinal explants cultured with cytokines (Figs. $4 \mathrm{D}, 4 \mathrm{E})$.

\section{Reduction of PTP1B in Retinal Cells Protected Against Inflammation-Mediated Inhibition of IGF- IR Signaling}

We have demonstrated that PTP1B inhibition restored hepatic insulin sensitivity in several in vivo models of insulin resistance. ${ }^{28,40,41}$ On that basis, we investigated the effect of cytokines on IGF-IR-mediated signaling in retinal cells with reduced PTP1B expression using siRNA. Protein tyrosine phosphatase 1B protein content was decreased by almost $90 \%$ in $661 \mathrm{~W}$ cells transfected with PTP1B siRNA (Fig. 5A). Then, we analyzed IGF-IR-mediated signaling in the presence of cytokines and we found that PTP1B silencing maintained IGF-IR tyrosine phosphorylation and Akt (serine 473) phosphorylation in the presence of cytokines compared with the reduced responses of the control (scrambled) condition. In cells transfected with scrambled siRNA, IGF-I-mediated IGF-IR phosphorylation was reduced by 4 -fold when they were pretreated with cytokines (CKI SC versus I SC; Figs. 5B, 5C). Moreover, in cells transfected with PTP1B siRNA, IGF-Imediated IGF-IR phosphorylation in the presence of cytokines was 5-fold higher than the response of this condition in the scrambled siRNA treatment (CKI siRNA PTP1B versus CKI SC). Regarding Akt, IGF-I-mediated phosphorylation at serine 473 was reduced by 7.6-fold when cells were pretreated with cytokines (CKI SC versus I SC). By contrast, in cells transfected with PTP1B siRNA this response was 8.2-fold increase compared with this condition in the scrambled siRNA treatment (CKI siRNA PTP1B versus CKI SC).

In mouse retinal explants, PTP1B siRNA efficiently reduced almost 70\% PTP1B protein levels (Fig. 5D) and improved IGFIR/Akt-mediated signaling in the presence of cytokines. Insulinlike growth factor-I-mediated Akt phosphorylation at serine 473 was reduced by 3.6-fold when retinal explants were pretreated with cytokines (CKI SC versus I SC; Figs. 5E, 5F). In retinal explants transfected with PTP1B siRNA, IGF-I-mediated Akt serine 473 phosphorylation in the presence of cytokines 
A

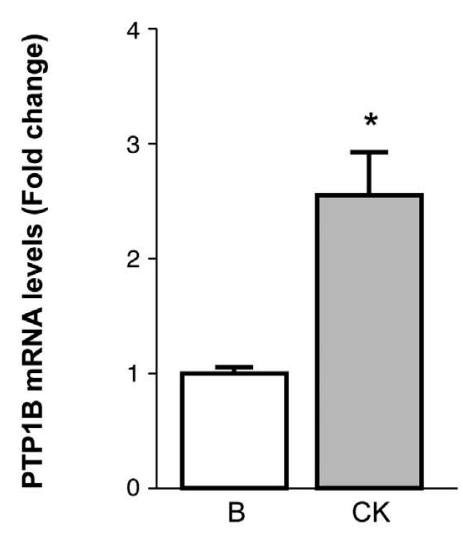

B
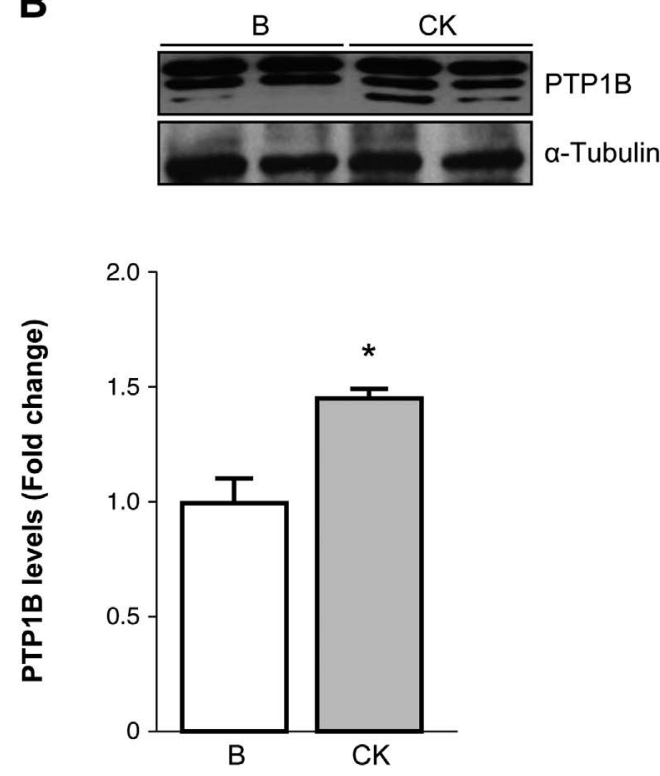

C

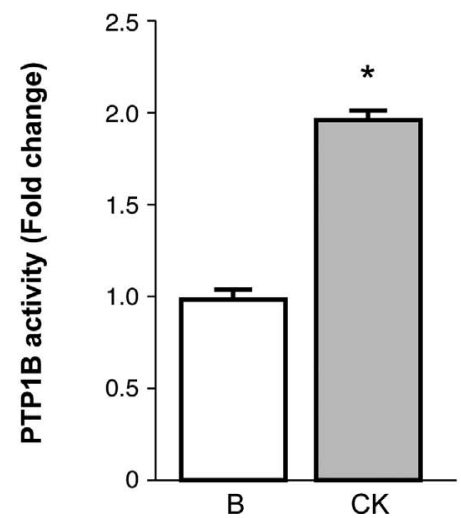

D

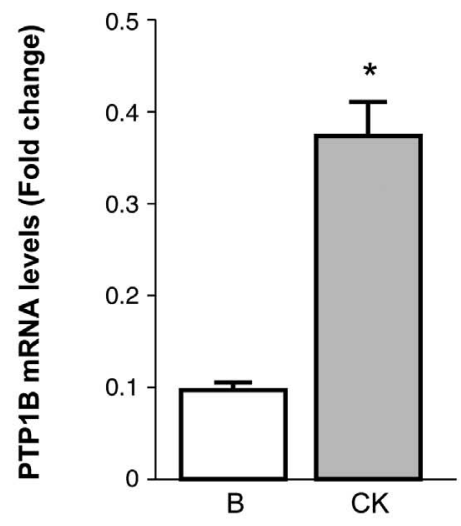

$\mathbf{E}$
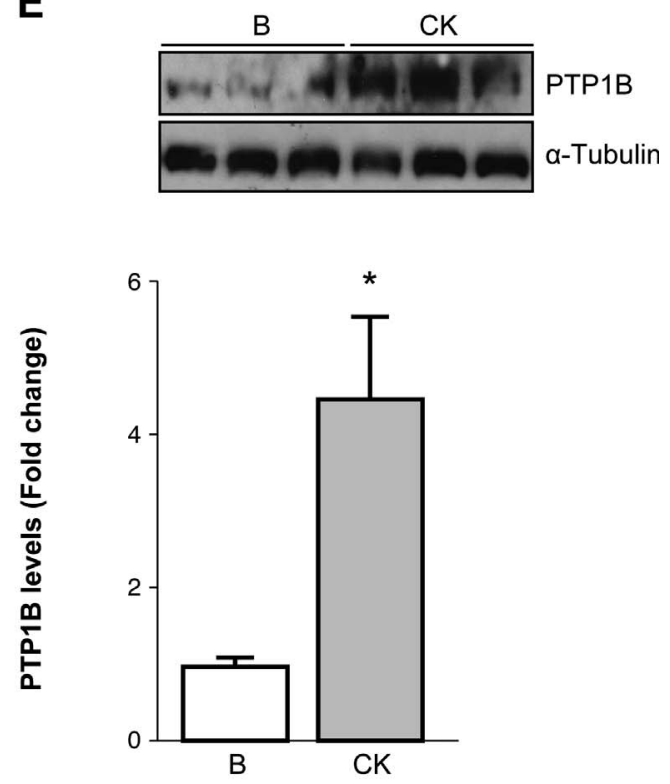

Figure 4. Protein tyrosine phosphatase 1B expression is upregulated in retinal cells and retinal explants cultured under proinflammatory conditions. (A-C) For 24 hours, $661 \mathrm{~W}$ cells were treated with cytokines (CK; $20 \mathrm{ng} / \mathrm{mL}$ ). (A) Protein tyrosine phosphatase $1 \mathrm{~B}$ mRNA levels were determined by real-time PCR. Used as a control was $18 S$ RNA. Results are expressed as $2^{-\Delta C t}$. (B) Protein extracts $(50 \mu \mathrm{g})$ were separated by SDS-PAGE and analyzed by Western blot with the anti-PTP1B antibody (Ref. 05-1087; Millipore). Alpha-tubulin was used as a loading control. Representative autoradiograms are shown. (C) Protein tyrosine phosphatase 1B enzymatic activity was analyzed as described in Materials and Methods. The results of PTP1B enzymatic activity are expressed as picomoles of released phosphate $/ \mathrm{min} / \mathrm{g}$ protein. The results are means \pm SEM ( $n=5$ independent experiments). Data were analyzed by Student's paired $t$-test; ${ }^{*} P \leq 0.05$ cytokines (CK) versus nonstimulated basal (B). Retinal explants were treated with cytokines (CK; 20 ng/ $\mathrm{mL}$ ) for 24 hours. (D) Protein tyrosine phosphatase 1B mRNA levels were determined by real-time PCR. Used as a control was 185 RNA. Results are expressed as $2^{-\Delta \mathrm{Ct}}$. (E) Protein extracts $(50 \mu \mathrm{g})$ were separated by SDS-PAGE and analyzed by Western blot with the anti-PTP1B antibody (Ref. 05-1087; Millipore). Alpha-tubulin was used as a loading control. The results are expressed as fold change and are means \pm SEM $(n=12$ independent retinas per condition). Data were analyzed by Student's paired $t$-test. Comparisons were ${ }^{*} P \leq 0.05$ cytokines (CK) versus nonstimulated basal (B). 
A
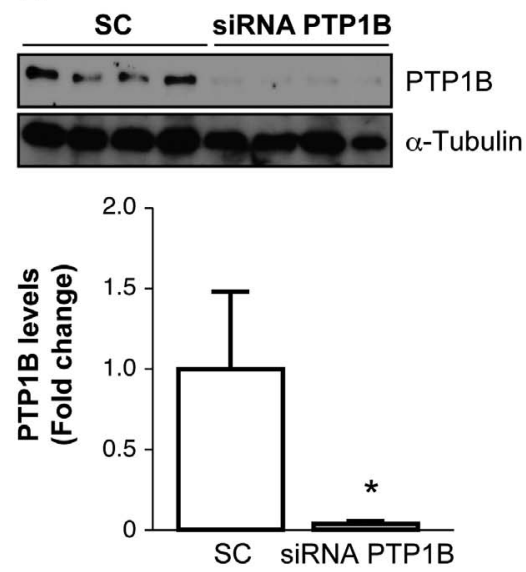

D
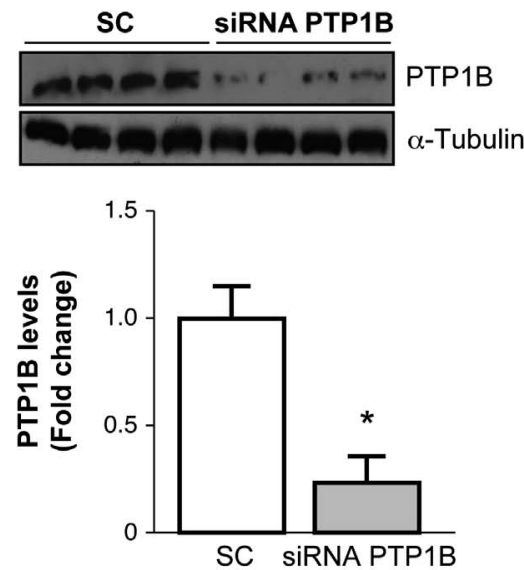

G

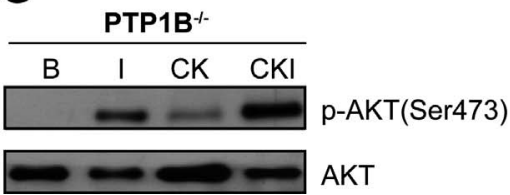

B

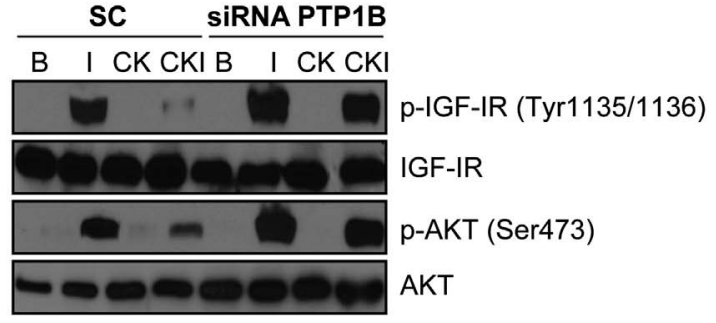

C

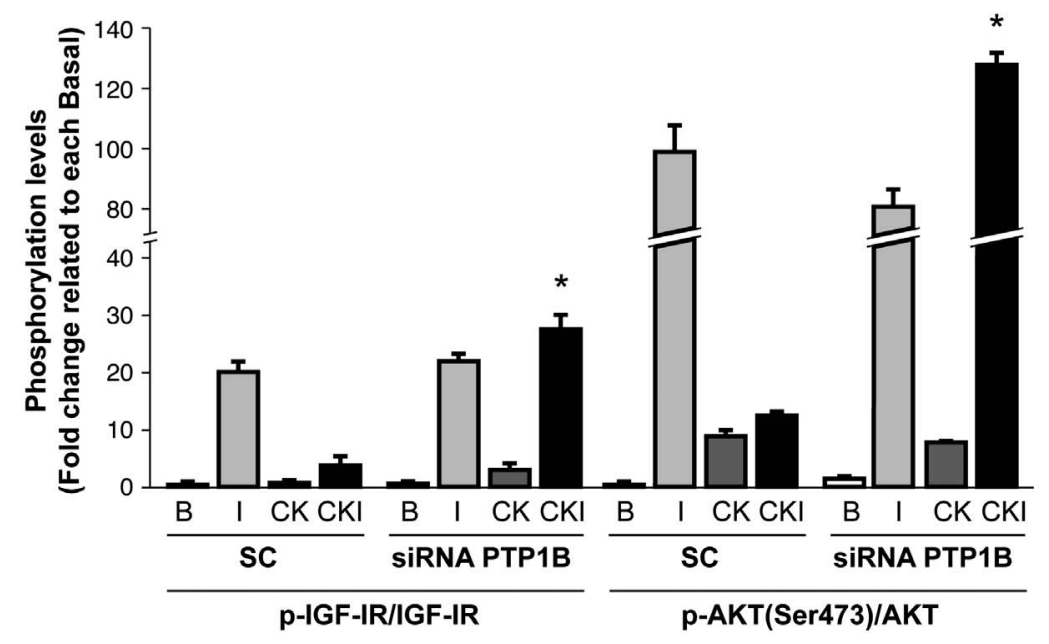

E

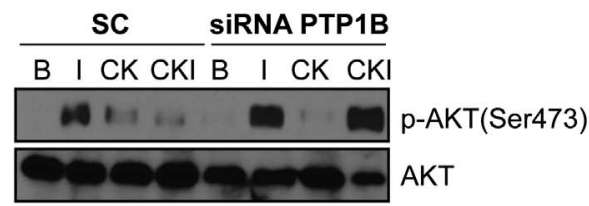

F

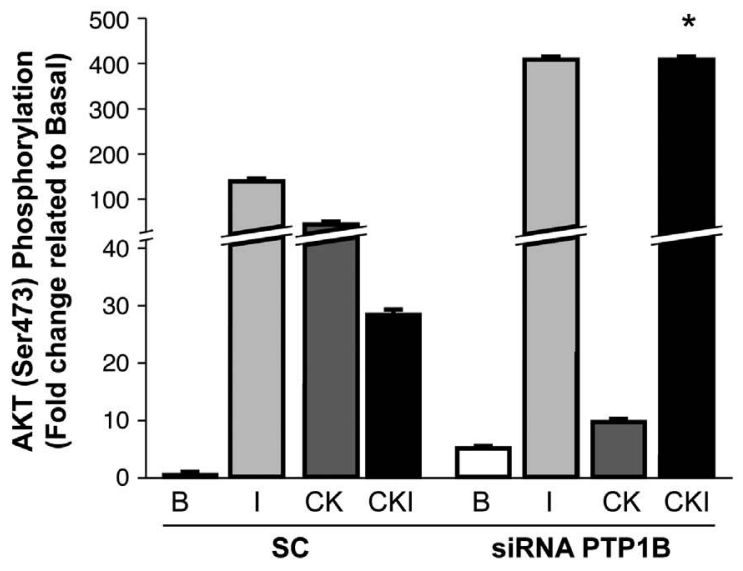

FIGURE 5. Reduction of PTP1B levels by siRNA in retinal cells protected against inflammation-mediated inhibition of IGF-IR signaling. (A) Efficiency of PTP1B siRNA in decreasing PTP1B levels in 661W cells. (B, C) For 36 hours, 661W cells were transfected with scrambled or PTP1B siRNA oligonucleotides and transfected cells were treated with cytokines (CK; $20 \mathrm{ng} / \mathrm{mL}$ ) for 24 hours, serum-starved for 2 hours and further stimulated with IGF-I (10 nM) for 15 minutes. (D) Efficiency of PTP1B siRNA in decreasing PTP1B in retinal explants. (E, F) Retinal explants were treated with siRNAs and stimulated as described for $661 \mathrm{~W}$ cells. (G) Retinal explants from PTP1B ${ }^{-1}$ mice were stimulated with cytokines and IGF-I as indicated above. Protein extracts $(50 \mu \mathrm{g})$ were separated by SDS-PAGE and analyzed by Western blot with the corresponding antibodies: anti-PTP1B (Ref. 07088; Millipore), anti-phospho IGF-IR (Tyr 1135/1136), anti-IGF-IR, anti-phospho Akt (Ser473), anti-Akt, and anti- $\alpha$-tubulin. Representative autoradiograms are shown $(n=5$ independent experiments or retinas per experimental condition). Autoradiograms were quantitated by scanning 
densitometry. Levels of phosphorylated proteins (pIGF-IR and pAkt) were normalized by levels of corresponding total (IGF-IR and Akt) proteins that were used as loading controls. These results are expressed as fold change of IGF-I stimulation related to each basal. Levels of PTP1B were normalized by $\alpha$-tubulin. The results are means \pm SEM. In (A) and (D), data were analyzed by paired $t$-test and comparisons were ${ }^{*} P \leq 0.05$ siRNA PTP1B versus scrambled siRNA (SC). In (C) and (F), data were analyzed by 1 - or 2 -way ANOVA followed by Bonferroni $t$-test. Comparisons were ${ }^{*} P \leq 0.05$ CKI siRNA PTP1B versus CKI SC.

was 13.3-fold higher than the response of this condition in the scrambled siRNA treatment (CKI siRNA PTP1B versus CKI SC).

To reinforce data obtained with siRNA in a genetic modified mouse model, we prepared retinal explants from PTP1Bdeficient mice $\left(\mathrm{PTP} 1 \mathrm{~B}^{-1-}\right)$ as previously reported. ${ }^{26}$ Interestingly, the treatment with cytokines did not reduce the response to IGF-I regarding Akt phosphorylation in retinas from $\mathrm{PTP}_{1 \mathrm{~B}}{ }^{-1-}$ mice (Fig. 5G).

We did not detect cell death in either $661 \mathrm{~W}$ cells or retinal explants transfected with siRNA (results not shown).

\section{Pharmacologic Inhibition of PTP1B Reduced Reactive Gliosis in Retinal Explants Treated With Cytokines}

Neurodegenerative diseases of the retina, including AMD, DR, and glaucoma involve chronic and dysregulated neuroinflammation and reactive gliosis. ${ }^{42,43}$ To get insight into the benefit of PTP1B inhibition in the whole retina under proinflammatory conditions, we evaluated the effect of cytokines on reactive gliosis in the ex vivo model of mouse retinal explants. Treatment with cytokines for 24 hours increased GFAP expression analyzed by Western blot by 4.5 -fold (Fig. 6A) and also increased GFAP staining (10-fold) in live retinal explants (Fig. 6B) indicating that, in the retina, cytokine-mediated reactive gliosis concurred with disruption of the IGF-IRmediated signaling cascade. We also analyzed the effect of pharmacologic inhibition of PTP1B in reactive gliosis. Cotreatment with cytokines and the PTP1B inhibitor used at $10 \mu \mathrm{M}$ as described $^{44}$ decreased by 2 -fold GFAP protein levels in mouse retinal explants (Fig. 6A).

\section{Pharmacologic Inhibition of PTP1B Reduced Reactive Gliosis in Retinal Explants From $d b / d b$ Mice}

It has been reported that diabetic $d b / d b$ mice presented systemic inflammation ${ }^{45}$ and reactive gliosis in the retina. ${ }^{3}$ On that basis, we analyzed PTP1B expression in retinas of these mice. Protein tyrosine phosphatase 1B mRNA and protein levels were increased by 1.8- and 3-fold, respectively, in retinas from $d b / d b$ mice compared with the lean $d b /+$ controls (Figs. 7A, 7B). Finally, we evaluated the efficacy of the PTP1B inhibitor against the reactive gliosis of $d b / d b$ mice. $^{3}$ As depicted in Figure 7C, GFAP immunostaining was decreased by 0.4 -fold in retinal explants from $d b / d b$ mice cultured with the PTP1B inhibitor for 24 hours.

\section{Discussion}

In chronic diseases of the retina linked to neuroinflammation, retinal macroglia, and microglia populations demonstrate activation and gliosis, ${ }^{46,47}$ which contribute to neurodegeneration in the neighbor retinal cells and, ultimately, in vision loss. ${ }^{4,48}$ Thus, unravelling the molecular mechanisms that confer protection to retinal cells against chronic neuroinflammation, as well as elucidating their therapeutic modulation, is of key importance. So far, current treatments for DR are applicable only at advanced stages and are associated with adverse effects. Therefore, new pharmacologic treatments aimed to combat retinal neuroinflammation associated to DR are urgently needed. This study provides evidence of the beneficial effect of targeting PTP1B in the retina in the IGF-IR/ Akt survival signaling pathway and reactive gliosis.

Although IGF-I has been recognized for its peripheral effects in growth and metabolism, it has a role in the CNS as a neurotrophic peptide triggering prosurvival signaling pathways responsible for activation of antiapoptotic cascades, enhancement of nerve growth, and promotion of synaptic plasticity. ${ }^{49}$ Moreover, IGF-IR signaling reduces neuroinflammation-dependent sensitivity of neurons to the proparkinsonian neurotoxin 1-methyl-4-phenyl-1,2,3,6-tetrahydropyridine (MPTP) ${ }^{50}$ In the retina, early intervention with systemic IGF-I in diabetic rats inhibits neuroretinal cell death. ${ }^{51}$ However, at the molecular level the impact of the chronic inflammatory environment, which is present in the retina in insulin resistance and T2DM, ${ }^{52}$ in the IGF-IR signaling in retinal cells has not been investigated in depth. Taking into account these previous findings, this study has identified for the first time a negative cross-talk between signaling pathways activated by the proinflammatory milieu and the IGF-IR/Akt neuroprotective pathway in photoreceptors that are major contributors to diabetes-induced local inflammation in the retina. ${ }^{53,54} \mathrm{We}$ found that $661 \mathrm{~W}$ cells are direct targets of proinflammatory cytokines as manifested by a rapid phosphorylation of JNK and p38 MAPK similar to that of peripheral cells during obesity. ${ }^{40,55,56}$ Because a previous report described that activation of JNK in response to light preceded apoptosis in $661 \mathrm{~W}$ cells, ${ }^{57}$ our results suggest that under conditions in which chronic inflammation reaches the retina, activation of stress kinases occur as it does in peripheral insulin-sensitive cells. In this regard, the feedback mechanism mediated by JNK responsible of the early phosphorylation of IRS1 at serine 307 that targets it for proteasomal degradation ${ }^{35}$ was found in photoreceptors and retinal explants cultured with proinflammatory cytokines. We have successfully used retinal organotypic cultures to characterize pathologic cell death during retinal degeneration. ${ }^{58}$ Herein, we made use of these cultures for elucidating the signaling pathways deregulated in DR. Considering these previous findings, long-term ( 24 hours) exposure of retinal cells and retinal explants to cytokines decreased IGF-IR tyrosine phosphorylation in response to IGF-I and triggered the degradation of IRS1. Intriguing, increased Akt phosphorylation was found in retinal explants treated with cytokines. This might result of compensatory mechanisms that could alter the expression or activity of specific serine phosphatases attempting to counteract the deleterious effects of cytokines. Nevertheless, under these conditions IGF-I was not able to further increase Akt phosphorylation, reflecting the profound IGF-I resistance induced by the proinflammatory milieu. Altogether, our results suggest a negative cross-talk between signaling pathways triggered by proinflammatory cytokines and IGFIR-mediated signaling in the retina at the level of IGF-IR and IRS1 that constitute a critical node of modulation of the insulin/IGF-I signaling network. ${ }^{12}$ This negative cross-talk was directly reflected by decreased Akt phosphorylation. Because 
A
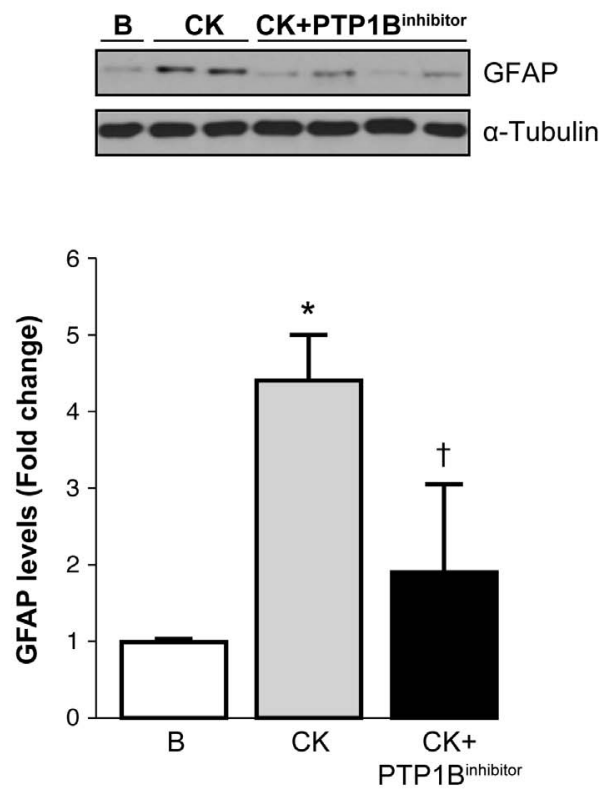

B
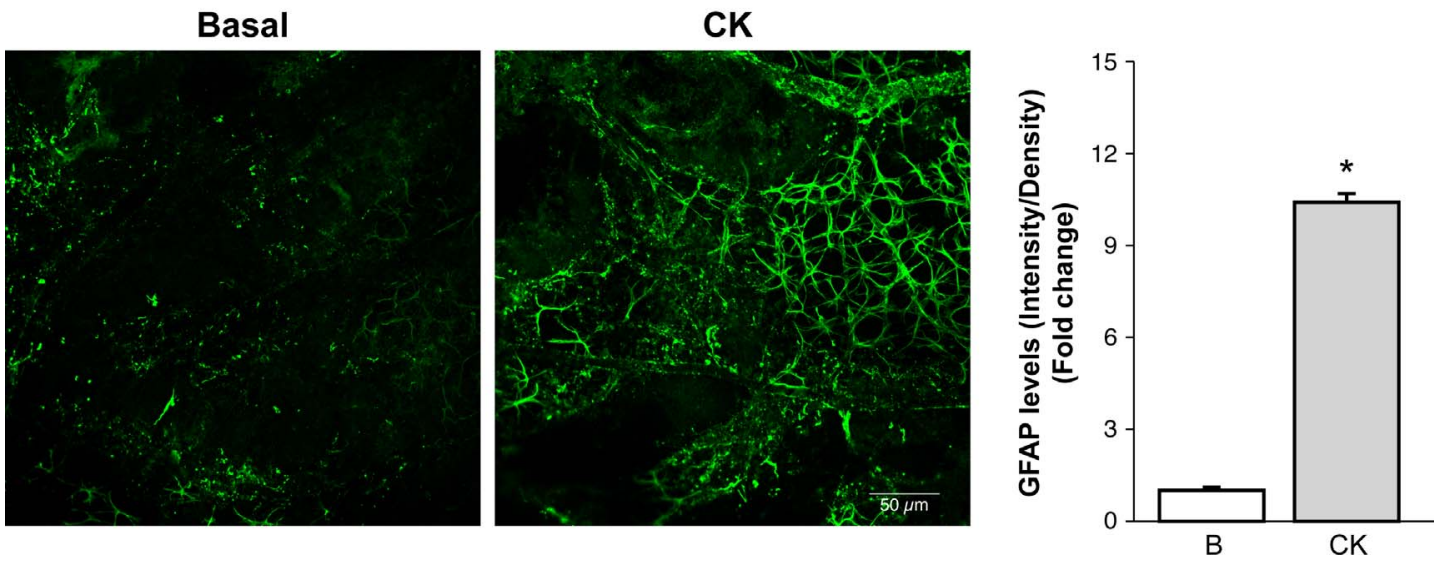

Figure 6. Pharmacologic inhibition of PTP1B reduced reactive gliosis induced by proinflammatory cytokines in retinal explants. Whole retinas were obtained from 10-week-old mice and cultured with cytokines (CK; $20 \mathrm{ng} / \mathrm{mL}$ ) for 24 hours in the presence or absence of the PTP1B inhibitor $(10 \mu \mathrm{M})$. (A) Protein extracts $(50 \mu \mathrm{g})$ were separated by SDS-PAGE and analyzed by Western blot with the corresponding antibodies against GFAP and $\alpha$-tubulin that was used as a loading control. Representative autoradiograms are shown. Autoradiograms corresponding to GFAP levels were quantitated by scanning densitometry. The results are means \pm SEM $(n=5$ retinas per experimental condition). Data were analyzed by 1 -way ANOVA followed by Bonferroni $t$-test. Comparisons were ${ }^{*} P \leq 0.05$ cytokines (CK) versus basal (B); $\nmid P \leq 0.05$ CK plus PTP1B inhibitor versus CK (B) Whole retinas were obtained from 10-week-old mice, cultured as described in (A) an immunostaining for GFAP (green) was carried out. Five retinas per experimental condition were analyzed. Representative confocal images are shown. Quantification of immunofluorescence was performed as described in Methods. Data were analyzed by paired $t$-test. Comparisons were ${ }^{*} P \leq 0.05$ CK versus basal (B)

it has been demonstrated that the neuroprotective action of IGF-I in vivo is most likely mediated by the PI 3-kinase/Akt pathway, ${ }^{59}$ our data strongly suggest that the proinflammatory milieu in the retina might compromise the fate of retinal cells.

Protein tyrosine phosphatase $1 \mathrm{~B}$ has emerged as a negative modulator of IR/IGF-IR tyrosine phosphorylation but most studies have focused on its role in inflammation linked to obesity and T2DM. ${ }^{39}$ In the retina, Rajala and coworkers ${ }^{60}$ demonstrated a negative modulation of IR tyrosine phosphorylation by PTP1B in diabetic mice and, conversely, enhanced IR phosphorylation in rod photoreceptors from PTP1B-deficient mice under light stress. ${ }^{25}$ As reported in fibroblasts, ${ }^{21}$ we have demonstrated that PTP1B modulates IGF-IR tyrosine phosphor- ylation in the retina. ${ }^{26}$ Thus, all these evidences prompted us to investigate the role of PTP1B in the retina under proinflammatory conditions. In $661 \mathrm{~W}$ cells treated with proinflammatory cytokines both PTP1B mRNA protein levels and its enzymatic activity were elevated and this effect was also reflected in the whole retina. Interestingly, treatment of $661 \mathrm{~W}$ cells with cytokines induced a cleavage of PTP1B similar to that reported in platelets that resulted in increased enzymatic activity. ${ }^{38}$

Based on our previous work in which PTP1B deficiency enhanced the IGF-IR/Akt-mediated signaling in mouse retina, ${ }^{26}$ we used PTP1B siRNA to transiently decrease PTP1B in retinal cells and avoid constitutive adaptations of genetic deletion. This approach allowed us to maintain IGF-I responsiveness of 
A

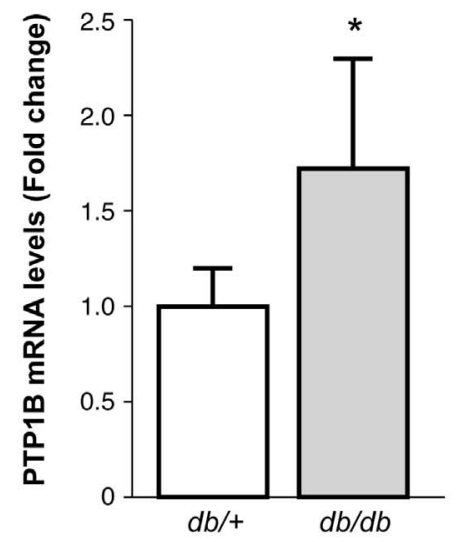

C

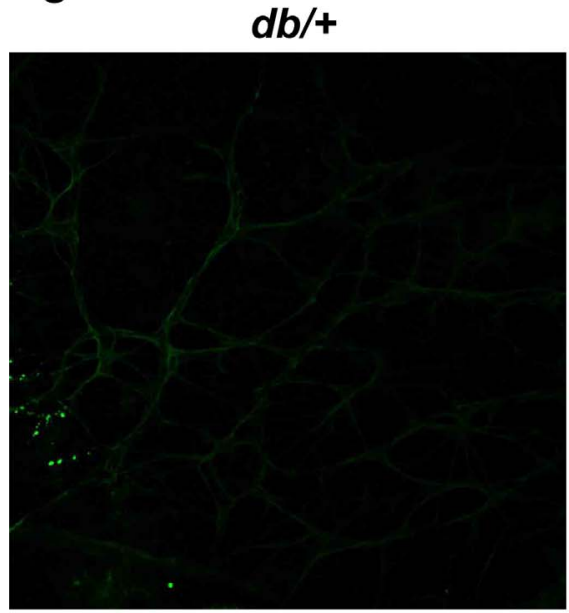

$d b / d b$ Basal

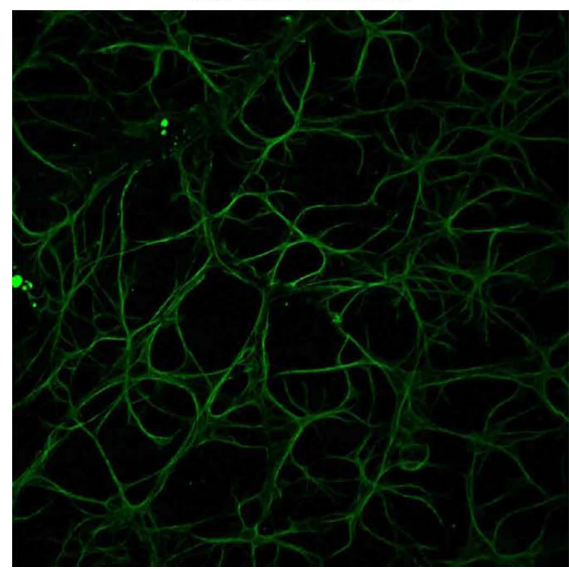

B
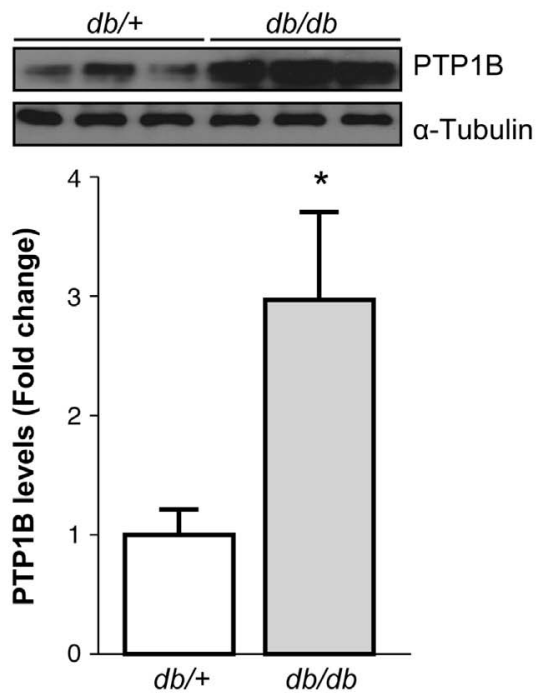

$d b / d b$
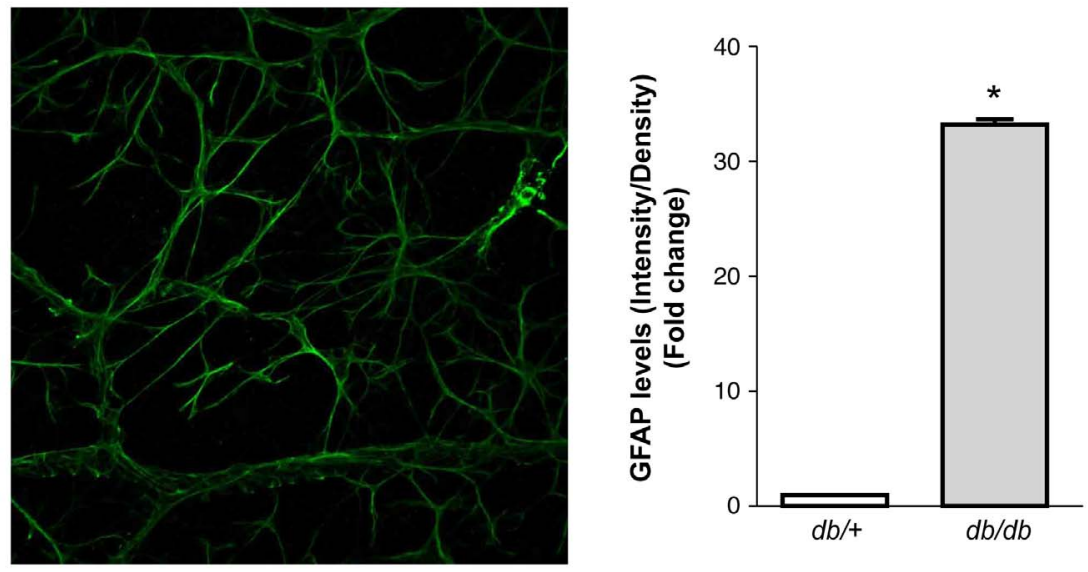

$d b / d b+P T P 1 B^{\text {inhibitor }}$
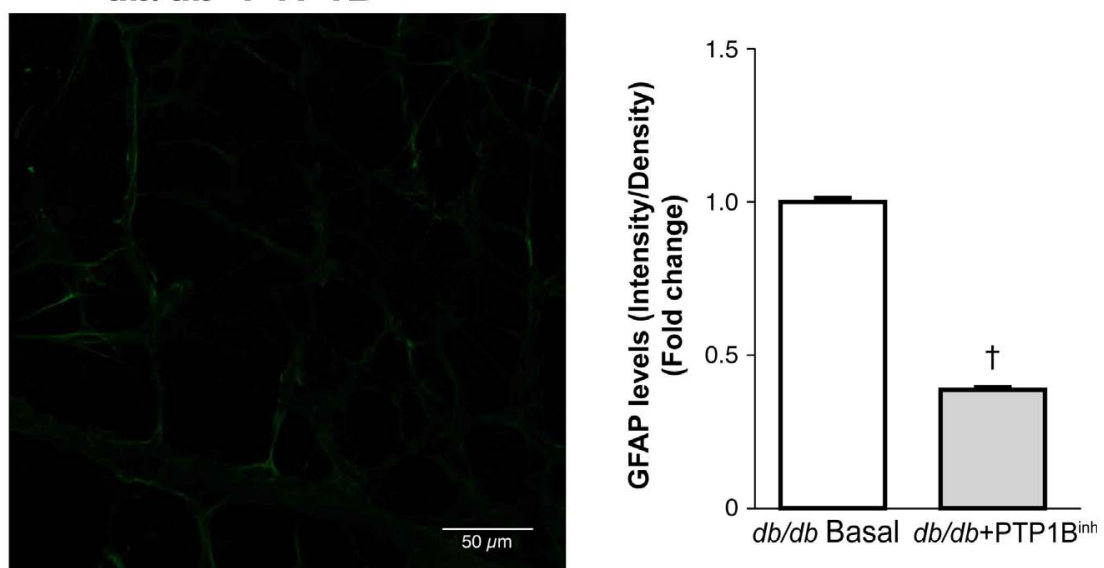

FIGURE 7. Pharmacologic inhibition of PTP1B reduced reactive gliosis in $d b / d b$ mice. Whole retinas were obtained from 10-week-old $d b /+$ and $d b /$ $d b$ mice. (A) Protein tyrosine phosphatase 1B mRNA levels were determined by real-time PCR. As a control, 18S RNA was used. Results are expressed as $2^{-\Delta \mathrm{Ct}}$. (B) Protein extracts $(50 \mu \mathrm{g})$ were separated by SDS-PAGE and analyzed by Western blot with the anti-PTP1B antibody (Ref. 051087; Millipore). Alpha-tubulin was used as a loading control. Representative autoradiograms are shown. The results are means \pm SEM $(n=12$ independent retinas per condition). Data were analyzed by Student's paired $t$-test. Comparisons were ${ }^{*} P \leq 0.05 d b / d b$ versus $d b /+$. (C) Immunostaining for GFAP (green) was carried out in retinas from $d b /+$ and $d b / d b$ mice (upper panels) and in retinas from $d b / d b$ mice were cultured for 24 hours in the presence or absence of the PTP1B inhibitor $(10 \mu \mathrm{M}$; lower panels). Five retinas per experimental condition were analyzed. Representative images are shown. Quantification of immunofluorescence was performed as described in Methods. Data were analyzed by paired $t$-test. Comparisons were * $P \leq 0.05 d b / d b$ versus $d b /+$ and $\dagger P \leq 0.05 d b / d b$ PTP1B inhibitor versus $d b / d b$ basal. 
$661 \mathrm{~W}$ cells in the presence of proinflammatory cytokines as reflected by increased levels of IGF-IR and Akt phosphorylation compared with the scrambled condition. The pathophysiological relevance of these results was assessed in retinal explants in which we were able to reduce PTP1B levels by siRNA and recover IGF-IR/Akt sensitization in a proinflammatory environment as in the retinas from $\mathrm{PTP}_{1} \mathrm{~B}^{-/}$mice. We previously reported that PTP1B deficiency rescued IGF-IR tyrosine phosphorylation, but not Akt phosphorylation, in retinas from diabetic IRS2-deficient mice due to elevated PTEN levels. ${ }^{26}$ However, results presented herein indicate that PTP1B silencing maintained IGF-IR-mediated Akt phosphorylation in the presence of an inflammatory environment. An explanation for these differences could be the lack of effect of proinflammatory cytokines in modulating PTEN in retinal cells and explants (data not shown), suggesting the importance of this inositol phosphatase in blocking the pathway specifically upstream of Akt.

Insulin/IGF-I resistance links obesity and/or T2DM to neurodegeneration, which has far-reaching effects in the CNS. ${ }^{6,61}$ In fact, both peripheral and central insulin resistance may be boosted by the chronic inflammatory environment associated with obesity. On the other hand, low serum IGF-I input to the brain may also exacerbate gliosis as IGF-I is involved in the inflammatory responses of glial cells. ${ }^{62}$ In this regard, our study has shown for the first time that a combination of proinflammatory cytokines is sufficient to induce reactive gliosis, monitored by levels of GAFP, in the retina and this effect is ameliorated by cotreatment with a PTP1B inhibitor, which might act by enhancing IGF-IRmediated signaling as occurred in the insulin signaling. ${ }^{44}$ Although deleterious effects of high levels of IGF-I in the retina have been reported, ${ }^{63-65}$ our previous data in retinal explants from mice with retinitis pigmentosa that presented hallmarks of inflammation, showed that treatment with IGF-I for 24 hours ameliorated reactive gliosis. ${ }^{66}$ A step further, PTP1B expression was elevated in the retina of diabetic $d b / d b$ mice that showed systemic inflammation ${ }^{45}$ and reactive gliosis ${ }^{3}$ reinforcing the link between PTP1B and inflammation in the retina. Interestingly, reactive gliosis in retinal explants from $d b / d b$ mice was reduced by treatment with a PTP1B inhibitor. As reactive gliosis is present in $\mathrm{DR},{ }^{3,67-69}$ our results might have therapeutic implications proposing a novel strategy for its treatment based on the specific inhibition of PTP1B in the retina.

In conclusion, our results show that retinal cells respond to the proinflammatory environment triggering signaling cascades that interfere with the IGF-IR/Akt survival pathway and induce reactive gliosis. These effects can be prevented by reducing PTP1B levels and strongly suggest that targeting this phosphatase might be useful for modulating the beneficial effects of IGF-I in the inflammatory states during DR.

\section{Acknowledgments}

The authors thank the animal facility staff (IIB Alberto Sols, CSIC) for technical assistance, Lucía Sánchez-Ruiloba and Diego Navarro for assistance with microscopy, and Patricia Boya (CSIC, Spain) for critical reading of the manuscript.

Supported by grants from Spanish Ministry of Economy and Competitivity (SAF2012-33283; Madrid, Spain), Comunidad de Madrid S2010/BMD-2423 (Madrid, Spain), Centro de Investigación Biomédica en Red de Diabetes y Enfermedades Metabólicas Asociadas (CIBEDEM, Instituto Carlos III, Madrid, Spain), and European Union (EUROCONDOR; FP7 HEALTH.2011.2.4.3.1.; Barcelona, Spain).

Disclosure: A.I. Arroba, None; A.M. Valverde, None

\section{References}

1. Pascolini D, Mariotti SP. Global estimates of visual impairment: 2010. Br J Ophthalmol. 2012;96:614-618.

2. Sivaprasad S, Gupta B, Crosby-Nwaobi R, Evans J. Prevalence of diabetic retinopathy in various ethnic groups: a worldwide perspective. Surv Ophthalmol. 2012;57:347-370.

3. Bogdanov P, Corraliza L, Villena JA, et al. The $\mathrm{db} / \mathrm{db}$ mouse: a useful model for the study of diabetic retinal neurodegeneration. PLoS One. 2014;9:e97302.

4. Simo R, Hernandez C; for the European Consortium for the Early Treatment of Diabetic Retinopathy. Neurodegeneration in the diabetic eye: new insights and therapeutic perspectives. Trends Endocrinol Metab. 2014;25:23-33.

5. Urbančič M, Štunf Š, Milutinovič Živin A, Petrovič D, GlobočnikPetrovič M. Epiretinal membrane inflammatory cell density might reflect the activity of proliferative diabetic retinopathy. Invest Ophthalmol Vis Sci. 2014;55:8576-8582.

6. Gregor MF, Hotamisligil GS. Inflammatory mechanisms in obesity. Annu Rev Immunol. 2011;29:415-445.

7. Purkayastha S, Cai D. Neuroinflammatory basis of metabolic syndrome. Mol Metab. 2013;2:356-363.

8. Ola MS, Nawaz MI, Siddiquei MM, Al-Amro S, Abu El-Asrar AM. Recent advances in understanding the biochemical and molecular mechanism of diabetic retinopathy. $J$ Diabetes Complications. 2012;26:56-64.

9. Okada S, Nakamura M, Mikami Y, et al. Blockade of interleukin6 receptor suppresses reactive astrogliosis and ameliorates functional recovery in experimental spinal cord injury. $J$ Neurosci Res. 2004;76:265-276.

10. Tilgner J, Volk B, Kaltschmidt C. Continuous interleukin-6 application in vivo via macroencapsulation of interleukin-6expressing COS-7 cells induces massive gliosis. Glia. 2001;35: 234-245.

11. Zhong Y, Li J, Chen Y, Wang JJ, Ratan R, Zhang SX. Activation of endoplasmic reticulum stress by hyperglycemia is essential for Müller cell-derived inflammatory cytokine production in diabetes. Diabetes. 2012;61:492-504.

12. Taniguchi CM, Emanuelli B, Kahn CR. Critical nodes in signalling pathways: insights into insulin action. Nat Rev Mol Cell Biol. 2006;7:85-96.

13. White MF. Regulating insulin signaling and beta-cell function through IRS proteins. Can J Physiol Pharmacol. 2006;84:725737.

14. Waldbillig RJ, Fletcher RT, Somers RL, Chader GJ. IGF-I receptors in the bovine neural retina: structure, kinase activity and comparison with retinal insulin receptors. Exp Eye Res. 1988; 47:587-607.

15. Burren CP, Berka JL, Edmondson SR, Werther GA, Batch JA. Localization of mRNAs for insulin-like growth factor-I (IGF-I), IGF-I receptor, and IGF binding proteins in rat eye. Invest Ophthalmol Vis Sci. 1996;37:1459-1468.

16. Frade JM, Marti E, Bovolenta P, et al. Insulin-like growth factor-I stimulates neurogenesis in chick retina by regulating expression of the alpha 6 integrin subunit. Development. 1996;122: 2497-2506.

17. Spielman LJ, Little JP, Klegeris A. Inflammation and insulin/IGF1 resistance as the possible link between obesity and neurodegeneration. J Neuroimmunol. 2014;273:8-21.

18. Boura-Halfon S, Zick Y. Phosphorylation of IRS proteins, insulin action, and insulin resistance. Am J Physiol Endocrinol Metabol. 2009;296:E581-E591.

19. Guan J, Miller OT, Waugh KM, McCarthy DC, Gluckman PD. Insulin-like growth factor-1 improves somatosensory function and reduces the extent of cortical infarction and ongoing neuronal loss after hypoxia-ischemia in rats. Neuroscience. 2001;105:299-306 
20. Seely BL, Staubs PA, Reichart DR, et al. Protein tyrosine phosphatase $1 \mathrm{~B}$ interacts with the activated insulin receptor. Diabetes. 1996;45:1379-1385.

21. Buckley DA, Cheng A, Kiely PA, Tremblay ML, O'Connor R. Regulation of insulin-like growth factor type I (IGF-I) receptor kinase activity by protein tyrosine phosphatase 1B (PTP-1B) and enhanced IGF-I-mediated suppression of apoptosis and motility in PTP-1B-deficient fibroblasts. Mol Cell Biol. 2002;22: 1998-2010.

22. Buckley DA, Loughran G, Murphy G, Fennelly C, O'Connor R. Identification of an IGF-1R kinase regulatory phosphatase using the fission yeast Schizosaccharomyces pombe and a GFP tagged IGF-1R in mammalian cells. Mol Pathol. 2002;55:46-54.

23. Elchebly M, Payette P, Michaliszyn E, et al. Increased insulin sensitivity and obesity resistance in mice lacking the protein tyrosine phosphatase-1B gene. Science. 1999;283:1544-1548.

24. Klaman LD, Boss O, Peroni OD, et al. Increased energy expenditure, decreased adiposity, and tissue-specific insulin sensitivity in protein-tyrosine phosphatase 1B-deficient mice. Mol Cell Biol. 2000;20:5479-5489.

25. Rajala RV, Tanito M, Neel BG, Rajala A. Enhanced retinal insulin receptor-activated neuroprotective survival signal in mice lacking the protein-tyrosine phosphatase-1B gene. $J$ Biol Chem. 2010;285:8894-8904.

26. Arroba AI, Revuelta-Cervantes J, Menes L, et al. Loss of protein tyrosine phosphatase $1 \mathrm{~B}$ increases IGF-I receptor tyrosine phosphorylation but does not rescue retinal defects in IRS2deficient mice. Invest Ophthalmol Vis Sci. 2013;54:42154225.

27. Tan E, Ding XQ, Saadi A, Agarwal N, Naash MI, Al-Ubaidi MR. Expression of cone-photoreceptor-specific antigens in a cell line derived from retinal tumors in transgenic mice. Invest Ophthalmol Vis Sci. 2004;45:764-768.

28. González-Rodríguez Á, Mas Gutierrez JA, Sanz-González S, Ros M, Burks DJ, Valverde AM. Inhibition of PTP1B restores IRS1mediated hepatic insulin signaling in IRS2-deficient mice. Diabetes. 2010;59:588-599.

29. Moriarty P, Boulton M, Dickson A, McLeod D. Production of IGF-I and IGF binding proteins by retinal cells in vitro. $\mathrm{Br} \mathrm{J}$ Ophthalmol. 1994;78:638-642.

30. King GL, Goodman AD, Buzney S, Moses A, Kahn CR. Receptors and growth-promoting effects of insulin and insulin-like growth factors on cells from bovine retinal capillaries and aorta. J Clin Invest. 1985;75:1028-1036.

31. O'Connor R. Survival factors and apoptosis. Adv Biochem Eng Biotechnol. 1998;62:137-166.

32. Fayard E, Xue G, Parcellier A, Bozulic L, Hemmings BA. Protein kinase $\mathrm{B}(\mathrm{PKB} / \mathrm{Akt})$, a key mediator of the PI3K signaling pathway. Curr Top Microbiol Immunol. 2010;346:31-56.

33. Grigsby JG, Cardona SM, Pouw CE, et al. The role of microglia in diabetic retinopathy. $J$ Ophthalmol. 2014;2014:705783.

34. Leng S, Zhang W, Zheng Y, et al. Glycogen synthase kinase 3 beta mediates high glucose-induced ubiquitination and proteasome degradation of insulin receptor substrate $1 . J$ Endocrinol. 2010;206:171-181.

35. Aguirre V, Uchida T, Yenush L, Davis R, White MF. The c-Jun $\mathrm{NH}(2)$-terminal kinase promotes insulin resistance during association with insulin receptor substrate-1 and phosphorylation of Ser(307). J Biol Chem. 2000;275:9047-9054.

36. Copps KD, White MF. Regulation of insulin sensitivity by serine/threonine phosphorylation of insulin receptor substrate proteins IRS1 and IRS2. Diabetologia. 2012;55:25652582.

37. Miranda S, González-Rodríguez Á, García-Ramírez M, et al. Beneficial effects of fenofibrate in retinal pigment epithelium by the modulation of stress and survival signaling under diabetic conditions. J Cell Physiol. 2012;227:2352-2362.
38. Pasquet JM, Dachary-Prigent J, Nurden AT. Microvesicle release is associated with extensive protein tyrosine dephosphorylation in platelets stimulated by A23187 or a mixture of thrombin and collagen. Biochem J. 1998;333(pt 3):591-599.

39. Zabolotny JM, Kim YB, Welsh LA, Kershaw EE, Neel BG, Kahn BB. Protein-tyrosine phosphatase $1 \mathrm{~B}$ expression is induced by inflammation in vivo. J Biol Chem. 2008;283:14230-14241.

40. González-Rodríguez A, Más-Gutierrez JA, Mirasierra M, et al. Essential role of protein tyrosine phosphatase 1B in obesityinduced inflammation and peripheral insulin resistance during aging. Aging Cell. 2012;11:284-296.

41. Mobasher MA, de Toro-Martin J, González-Rodríguez Á, et al. Essential role of protein-tyrosine phosphatase $1 \mathrm{~B}$ in the modulation of insulin signaling by acetaminophen in hepatocytes. J Biol Chem. 2014;289:29406-29419.

42. Vohra R, Tsai JC, Kolko M. The role of inflammation in the pathogenesis of glaucoma. Surv Ophthalmol. 2013;58:311320.

43. Buschini E, Piras A, Nuzzi R, Vercelli A. Age related macular degeneration and drusen: neuroinflammation in the retina. Prog Neurobiol. 2011;95:14-25.

44. Ding H, Zhang Y, Xu C, et al. Norathyriol reverses obesity- and high-fat-diet-induced insulin resistance in mice through inhibition of PTP1B. Diabetologia. 2014;57:2145-2154.

45. Mayer C, Bergholdt R, Cucak H, Rolin BC, Sams A, Rosendahl A. Neutralizing anti-IL20 antibody treatment significantly modulates low grade inflammation without affecting HbA1c in type 2 diabetic db/db mice. PLoS One. 2015;10:e0131306.

46. Karlstetter M, Walczak Y, Weigelt $\mathrm{K}$, et al. The novel activated microglia/macrophage WAP domain protein, AMWAP, acts as a counter-regulator of proinflammatory response. J Immunol. 2010;185:3379-3390.

47. Bringmann A, Wiedemann P. Müller glial cells in retinal disease. Ophthalmologica. 2012;227:1-19.

48. Langmann T. Microglia activation in retinal degeneration. $J$ Leukocyte Biol. 2007;81:1345-1351.

49. Carro E, Trejo JL, Núñez A, Torres-Aleman I. Brain repair and neuroprotection by serum insulin-like growth factor I. Mol Neurobiol. 2003;27:153-162.

50. Nadjar A, Berton O, Guo S, et al. IGF-1 signaling reduces neuroinflammatory response and sensitivity of neurons to MPTP. Neurobiol Aging. 2009;30:2021-2030.

51. Seigel GM, Lupien SB, Campbell LM, Ishii DN. Systemic IGF-I treatment inhibits cell death in diabetic rat retina. $J$ Diabetes Complications. 2006;20:196-204.

52. Mima A, Qi W, Hiraoka-Yamomoto J, et al. Retinal not systemic oxidative and inflammatory stress correlated with VEGF expression in rodent models of insulin resistance and diabetes. Invest Ophthalmol Vis Sci. 2012;53:8424-8432.

53. Tu Z, Portillo JA, Howell S, et al. Photoreceptor cells constitutively express functional TLR4. J Neuroimmunol. 2011;230:183-187.

54. Du Y, Veenstra A, Palczewski K, Kern TS. Photoreceptor cells are major contributors to diabetes-induced oxidative stress and local inflammation in the retina. Proc Natl Acad Sci US A. 2013;110:16586-16591.

55. Vallerie SN, Hotamisligil GS. The role of JNK proteins in metabolism. Sci Trans Med. 2010;2:60rv65.

56. Czaja MJ. JNK regulation of hepatic manifestations of the metabolic syndrome. Trends Endocrinol Metabol. 2010;21: 707-713.

57. Yang LP, Zhu XA, Tso MO. Role of NF-kappaB and MAPKs in light-induced photoreceptor apoptosis. Invest Ophthalmol Vis Sci. 2007;48:4766-4776.

58. Arroba AI, Wallace D, Mackey A, de la Rosa EJ, Cotter TG. IGF-I maintains calpastatin expression and attenuates apoptosis in 
several models of photoreceptor cell death. Eur J Neurosci. 2009;30:975-986.

59. Kim W, Lee Y, McKenna ND, et al. miR-126 contributes to Parkinson's disease by dysregulating the insulin-like growth factor/phosphoinositide 3-kinase signaling. Neurobiol Aging. 2014;35:1712-1721.

60. Rajala RV, Wiskur B, Tanito M, Callegan M, Rajala A. Diabetes reduces autophosphorylation of retinal insulin receptor and increases protein-tyrosine phosphatase-1B activity. Invest Ophthalmol Vis Sci. 2009;50:1033-1040.

61. Hallschmid M, Schultes B. Central nervous insulin resistance: a promising target in the treatment of metabolic and cognitive disorders? Diabetologia. 2009;52:2264-2269.

62. Fernandez AM, Fernandez S, Carrero P, Garcia-Garcia M, Torres-Aleman I. Calcineurin in reactive astrocytes plays a key role in the interplay between proinflammatory and antiinflammatory signals. $J$ Neurosci. 2007;27:8745-8756.

63. Villacampa P, Ribera A, Motas S, et al. Insulin-like growth factor I (IGF-I)-induced chronic gliosis and retinal stress lead to neurodegeneration in a mouse model of retinopathy. $J$ Biol Chem. 2013;288:17631-17642.
64. Ruberte J, Ayuso E, Navarro M, et al. Increased ocular levels of IGF-1 in transgenic mice lead to diabetes-like eye disease. $J$ Clin Invest. 2004;113:1149-1157.

65. Haurigot V, Villacampa P, Ribera A, et al. Increased intraocular insulin-like growth factor-I triggers blood-retinal barrier breakdown. J Biol Chem. 2009;284:22961-22969.

66. Arroba AI, Alvarez-Lindo N, van Rooijen N, de la Rosa EJ. Microglia-Müller glia crosstalk in the rd10 mouse model of retinitis pigmentosa. Adv Exp Med Biol. 2014;801:373-379.

67. Carrasco E, Hernandez C, Miralles A, Huguet P, Farres J, Simo $R$. Lower somatostatin expression is an early event in diabetic retinopathy and is associated with retinal neurodegeneration. Diabetes Care. 2007;30:2902-2908.

68. Valverde AM, Miranda S, García-Ramírez M, GonzálezRodríguez Á, Hernández C, Simó R. Proapoptotic and survival signaling in the neuroretina at early stages of diabetic retinopathy. Mol Vision. 2013;19:47-53.

69. Biswal MR, Prentice H, Dorey CK, Blanks JCA. Hypoxia responsive glia cell-specific gene therapy vector for targeting retinal neovascularization. Invest Ophthalmol Vis Sci. 2014; 55:8044-8053. 